\title{
The Effect of the Decoction of Citrus aurantifolia (Lime) and Camellia sinensis (Lipton Tea) on the Plasma Glucose; Plasma Total Protein, Albumin Concentrations and Weight of Normal Albino Rats
}

\author{
Ojoye Preiye ${ }^{1}$, Tawari Erebi Patricia ${ }^{1}$, Boloya Vukumo Eric ${ }^{1}$, \\ Kasia Benedicta Erere', Prohp The Prophet ${ }^{2}$ \\ ${ }^{1}$ Department of Chemical Pathology, Faculty of Basic Medical Sciences, College of Health Sciences, Niger \\ Delta University, Bayelsa State, Nigeria. \\ ${ }^{2}$ Department of Biochemistry, Faculty of Basic Medical Sciences, College of Health Sciences, Niger Delta \\ University, Bayelsa State, Nigeria.
}

Corresponding Author: Tawari Erebi Patricia

\begin{abstract}
Citrus aurantifolia is one of the major fruit trees that grow throughout the world and it's known for its refreshing juice and health benefits. Some attributes of citrus aurantifolia (lime) include pharmacological properties (antitumor anti-inflammatory, anti-cancer). This study was aimed at determining the effects of the decoction of citrus aurantifolia and camellia sinensis (Lipton tea) on the glucose, plasma total protein and plasma albumin concentration in normal albino rats. Twentyfour (24) female healthy albino rats of Wister strain aged 3weeks and with an average of weight of $150 \mathrm{~g}$ were randomly placed into two [2] groups of twelve rats each (control and test) after acclimatization for one week. The lime and Lipton tea was administered orally to the test group for 14days. Blood samples were collected from each rats and analyzed spectrophotometrically for plasma glucose, total protein and albumin. The liver, heart and kidney tissues were collected also for histological studies. Analysis of result shows that the plasma glucose decreased significantly $(\mathrm{p}<0.05)$ and the histological report showed that the liver and the kidneys were affected adversely but had no effect on the heart; the plasma total protein decreased significantly $(\mathrm{p}<0.05)$ and had adverse affection on the liver and kidneys. There was no significant increase in plasma albumin [p>0.05], however histological report showed effect on the liver and kidneys. In conclusion the lime and Lipton tea can be clinically significant in the reduction of high plasma glucose levels in the management of diabetes mellitus, treatment of obesity due to its protein reducing ability and has effect on plasma albumin; however, concentrations and doses administered could have adverse effect on the liver and kidneys.
\end{abstract}

Key Words: Lime, Lipton tea, Glucose, Total protein, Albumin, Albino rats.

\section{INRODUCTION}

Herbal medicine and various types of plant-based therapeutic/prophylactic products have been available for centuries and applied in the treatment of diseases throughout history. Worldwide, phytomedicine and herbal medicine are culturally accepted and ubiquitously practice $^{[1]}$. The importance of these studies for guiding future herbal medicine cannot be overstated since most herbs consumed may have toxic effects and scientific reports of potential long term toxically of some commonly consumed herbs are emerging in the literature. The toxicological profile of any herb is dependent on its photochemistry and the prevailing micro environmental physical or chemical stressor. 
Tea after water is the most widely consumed beverages in the world ${ }^{[2]}$. Tea is generally consumed in the form of black, oolong or green tea which are all preparations originating from camellia sinensis, a small plant grown mainly in China and southeast Asia. Tea is cultivated in many countries worldwide and also consume globally. Black tea is consumed principally in Europe, North America and North Africa (except Morocco), while green tea is drunk throughout Asia; oolong tea is popular in china and Tiran. Green tea is rich in varieties of beneficial chemicals with maximum positive effects on human beings [3] Tea prepared from processed leaves of Camellia Sinensis and its supplements generally contain higher amount of disease fighting antioxidants called polyphones, almost of which are catechins. Catechins account for $10 \%-20 \%$ of dry green tea leaves and those are described as being responsible for the bitter components of green tea. The major types of catechins in green tea are epigallocatechinn gallate (EGCG), gallocatechin (GC), catechin gallate (CG), and gallocatechingallate (GCG). Among these EGCG has been extensively investigated since it is the dominant catechin in green tea ${ }^{[4]}$. Other components of green and white tea solid matter include vitamins (A, B1, B2, B3 and C) chlorophyll, various minerals, pectin, saccarides and saponiun freshly cut tea leaves consist of about $75 \%$ water ${ }^{[5]}$. Catechin makes up as much as $25 \%$ of the leaves dry matter ${ }^{[6]}$.

Numerous research studies have showed promising effect on tea's antibacterial, anti-inflammatory, protection against cancers, blood glucose lowering, and brain health cholesterol powering properties, antihypertensive weight loss, and many more. A particularly exciting discovery by Sanaka et al., ${ }^{[7]}$ demonstrated the antibacterial properties of the green tea polyphenols, their results showed that these compounds inhabit the growth and adherence of oral bacteria particularly periodontal causing bacterium porphyromonas and decay causing bacteria such as streptococcus salivarius and streptococcus mutants. Another study by Reygaert [8] also confirmed that streptococcus mutants are inhibited completely by contact with green tea polyphenols.

Scientific studies suggest that epigallocatechin gallate [EGCG], the major tea polyphenol along with other polyphenols have anti-inflammatory and anticancer properties that may help prevent the onset and growth of skin tumours ${ }^{[9]}$, women who consumed green tea experienced the least spread of cancer particular pre-menopause women with early stages of breast cancer ${ }^{[2]}$. Tea catechin especially EGCG, appear to have antidiabetic effects ${ }^{[10]}$. EGCG alone has the potential to increase fat oxidation in men and may thereby contribute to the antiobesity effects of green tea ${ }^{[11]}$. Catechin present in green tea has the antithyroidal as well as goitrogenic potential however regular consumption at relatively high doses pose a threat to the functioning of thyroid [12].

Tea can preserve the antioxidant defense system as Bhatt et al., attributed the consumption of green or oolong tea $120 \mathrm{ml}$ daily for a year or more, significantly reduced the risk of developing hypertension in the Chinese population. Green tea lowers total cholesterol and raises HDC cholesterol in both animal and people ${ }^{[13]}$ consumption of green tea reduces the risk of cardiovascular diseases ${ }^{[14]}$. Green tea possesses neuroprotective effects; polyphenols protect dopamine neurons ${ }^{[15]}$.

Citrus aurantifolia is a
polyembroyonic plant cultivated in many countries all over the world and grows in hot subtropical or tropical regions such as southern Florida, India, Mexico, Egypt and the West Indies. Citrus aurantifolia is commonly called lime in Nigeria. The plant belongs to the kingdom plantae, phylum, mangnothophyta, class mangnothopsida, order sapindales family putacea gems citrus and species citrus aurantifolia ${ }^{[16]}$. Citrus fruits are consumed worldwide in form of 
fresh fruit or are processed into citrus product and citrus by product such as dehydrated citrus product or marmalades, jams, sorbet, pickles, jellies, candies and sugar boiled ${ }^{[17]}$. Citrus aurantifolia fruit juice has been used to preservative for "Zobo" drink in Nigeria where it was reported to decrease the total coli form and other bacterial counts in "Zobo" drink ${ }^{[18]}$. C. aurantifolia in its natural state is used in West Africa, particular in Nigeria as herbal medicine to treat several illnesses; they are essential ingredient in the preparation of most herbal concoctions. The decoction of the bank of $C$. aurantifolia can help relief flatulence ${ }^{[19]}$ the diluted form of the $C$. aurantifolia fruit juice is used for mouth wash to treat sore mouth and sore throat ${ }^{[16]}$ in southwest Nigeria; the roots barks, sremtrings, leaves and fruit are used in the treatment of malaria ${ }^{[20]}$. The juice $C$. aurantifolia has been found to have antimycobacterial activities and anticancer effects ${ }^{[21]}$.

This research was conducted to examine the effects if decoction of Citrus aurantifolia (lime) and Camellia sinensis (Lipton Tea) on the Plasma Glucose; Plasma Total Protein, Albumin concentrations and weight of Normal Albino Rats.

\section{MATERIALS AND METHODS Materials}

Chemicals/reagents: all chemicals/reagents used were of analytical grade and are as manufactured by Randox laboratory life in England the kit and supplied by Pynex reagent a commercial supplier.

\section{Experimental animals}

About twenty-four (24) healthy female albino rats of wistar strain aged 3 weeks and with an average weight of $150 \mathrm{~g}$ were used for this study. They were obtained from the animal house of vilcare pharmaceutical, Port-Harcourt and maintained under standard laboratory conditions. The animals were acclimatized for one week and during this period were fed with pelleted growers marsh and clean distilled water.
The fresh lime specimen and Lipton tea were purchased from Amassoma Market, Bayelsa State.

\section{Methods \\ Preparation of extract}

Two (2) fresh limes were thoroughly washed with clean water and cut into pieces, they were then introduced into $500 \mathrm{ml}$ beaker containing $200 \mathrm{mls}$ of distilled water and a bag of Lipton tea. The mixture was allowed to boil for 20minutes, cooled at room temperature and then sieved with the aid of a sterile cheese cloth the extract was stored in a clean bottle and kept in the refrigerator at $4^{\circ} \mathrm{C}$ and subsequently administered to the rats, this procedure was repeatedly done to have a routine fresh sample.

\section{Administration of extract}

The decoction of lime and Lipton tea were administration to the experimental animals orally [p.o] using a gavage at $2 \mathrm{ml} / \mathrm{kg}$ body weight of rat three times daily, 8 hourly.

\section{Experimental Design}

The 24 healthy female albino rats of wistar strain were randomly distributed into two groups about 12 rats each group. Group 1 served as control and received growers marsh and distilled water throughout the experiment. Group 2 serve as the test and was administrated experimental sample at $2 \mathrm{ml} / \mathrm{kg}$ body weight and also fed with growers marsh and clean distilled water throughout the experiment

Assays of Group 1 and Group 2 samples. Glucose was determined after enzymatic oxidation in the presence of glucose oxide as described by Randox Laboratories Limited, England. The hydrogen peroxide formed reacts under the catalysis of the peroxidase with the phenol and 4-aminopherazone to form a red-violet quinomine dye as indicator. Exactly 10ul of the plasma of the red blood collected in a fluoride oxalate bottle was transferred into test tube containing 1000ul of the reagent. Samples 
were thoroughly mixed and incubated at $37^{\circ} \mathrm{C}$ for 10 minutes. The absorbance values were read at $540 \mathrm{~nm}$ using the glucose blank as the blank.

The total proteins and albumin were determined by the Biuret and Bromocresol green methods respectively.

\section{Ethical Clearance}

The entire experimental protocol was performed in accordance with the Institutional Animal Ethical Committee (IAEC), in line with the directions of the Committee for the Purpose of Control and Supervision of Experiments on Animals (CPCSEA) in Niger Delta University, Wilberforce Island, Bayelsa State, Nigeria.

\section{Blood collection}

Experimental rats were sacrificed periodically for blood collection was immediately subjected to at 3000xg for 20minutes to obtain the plasma.

\section{Histological Assessment of Tissue}

The rats were sacrificed periodically and dissected to obtain the heart, liver and kidney for histological studies. The tissue samples were immediately preserved by immersion into $10 \%$ formalin. The fixed tissue samples were cleared in xylene and embedded in paraffin wax and sections were cut using 5-micro in a rotator microtome. The sections were then examined using the light microscopy after staining with hematoxylin and eosin dye for general tissue structures and interpreted by a histologist.

\section{Statistical Analysis}

Results are presented as mean \pm standard error of three separate determinations. Statistical analysis was performed using ANOVA. $\mathrm{P}<0.05$ indicated statistical significance.

\section{RESULTS}

Results are presented in table 1 and figures 1-3. Photo micrographs of histological studies are presented as figures 1-3 of both control and test.

From table 1 the mean plasma glucose concentrations, total protein, albumin and weight of female albino rats following oral administration of the decoction [lime and Lipton tea] for 14 days showed that the plasma glucose of the test rats significantly increased on day 7 and day 14 of experiment relative to the normal control $[p<0.05]$, the plasma total protein decreased significantly [ $p<0.05]$ from day 1 to day 14 compared to the control, the plasma albumin concentration has no significant increase [ $p>0.05]$ compare to the control.

The control group experienced a steady increase in body weights[g] throughout the period however when compared with the test values the increase observed were not significant [ $p>0.05]$.

Table 1. Mean plasma glucose, total protein, albumin concentrations and weight of normal albino rats respectively.

\begin{tabular}{|c|c|l|l|l|l|}
\hline \multicolumn{2}{|c|}{ DAYS } & $\begin{array}{l}\text { GLUCOSE } \\
\text { conc. mg/dl }\end{array}$ & TOTAL PROTEIN g/d & ALBUMIN mg/dl & $\begin{array}{l}\text { WEIGHT } \\
\text { G }\end{array}$ \\
\hline 0 & $\mathrm{C}$ & $58.60 \pm 0.09^{\mathrm{a}}$ & $36.26 \pm 1.59^{\mathrm{a}}$ & $3.38 \pm 0.02^{\mathrm{a}}$ & $133.53 \pm 4.67^{\mathrm{a}}$ \\
& $\mathrm{T}$ & $57.91 \pm 0.20^{\mathrm{a}}$ & $37.26 \pm 1.63^{\mathrm{a}}$ & $3.34 \pm 0.01^{\mathrm{a}}$ & $146.07 \pm 3.24^{\mathrm{b}}$ \\
\hline 1 & $\mathrm{C}$ & $58.50 \pm 0.80^{\mathrm{a}}$ & $38.78 \pm 2.75^{\mathrm{b}}$ & $3.40 \pm 0.01^{\mathrm{a}}$ & $138.78 \pm 14.19^{\mathrm{a}}$ \\
& $\mathrm{T}$ & $55.02 \pm 1.22^{\mathrm{a}}$ & $29.92 \pm 0.96^{\mathrm{a}}$ & $3.44 \pm 0.01^{\mathrm{a}}$ & $149.52 \pm 12.53^{\mathrm{b}}$ \\
\hline 7 & $\mathrm{C}$ & $58.23 \pm 1.22^{\mathrm{b}}$ & $43.63 \pm 2.36^{\mathrm{b}}$ & $3.44 \pm 0.01^{\mathrm{a}}$ & $161.07 \pm 5.78^{\mathrm{a}}$ \\
& $\mathrm{T}$ & $44.34 \pm 0.46^{\mathrm{a}}$ & $23.14 \pm 0.68^{\mathrm{a}}$ & $3.43 \pm 0.01^{\mathrm{a}}$ & $139.4 \pm 16.95^{\mathrm{a}}$ \\
\hline 14 & $\mathrm{C}$ & $57.43 \pm 1.22^{\mathrm{b}}$ & $42.73 \pm 0.25^{\mathrm{b}}$ & $3.55 \pm 0.01^{\mathrm{a}}$ & $169.43 \pm 3.77^{\mathrm{a}}$ \\
& $\mathrm{T}$ & $35.26 \pm 0.80^{\mathrm{a}}$ & $22.13 \pm 1.29^{\mathrm{a}}$ & $3.58 \pm 0.03^{\mathrm{a}}$ & $155.93 \pm 18.22^{\mathrm{a}}$ \\
\hline
\end{tabular}

Values are presented as mean \pm STD triplicate determinations. Values with the same superscript alphabets are non-significant statistically.

Liver Histopathological sections of the liver of the control animal showed normal plates of hepatocytes separated by sinusoids unlike those of test animals that received the extract. Photomicrograph of the liver tissue showing central vein, hepatocytes and sinusoids consistent with normal histology of the liver. The TEST group shows infiltration of inflammatory cells around the central vein. Also seen are prominent Kupffer cells. Substance administered is hepatotoxic. 
Ojoye Preiye et.al. The effect of the decoction of citrus aurantifolia (LIME) and camellia sinensis (LIPTON TEA) on the plasma glucose; plasma total protein, albumin concentrations and weight of normal albino rats.

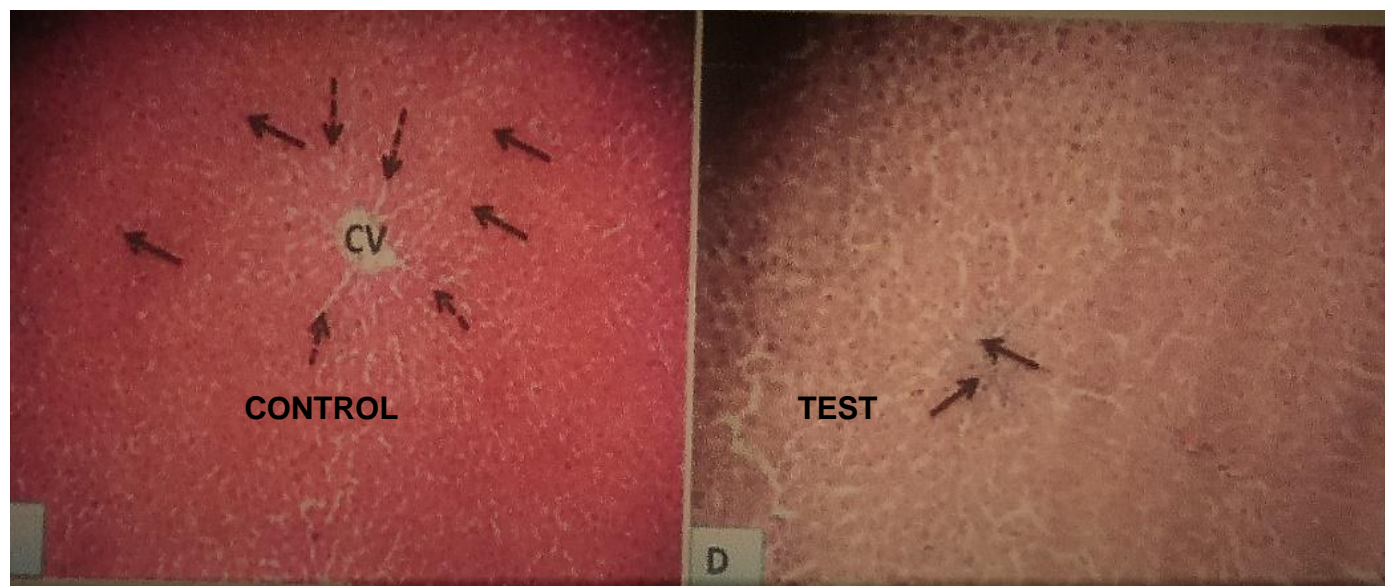

Figure 1: Haematoxylin and Eosin stain liver Tissue, X 400 Magnification

Kidney: Photomicrograph of the kidney tissue stained with haematoxylin and eosin. The CONTROL kidney slides showed normal glomerulus while the TEST slide membranous defeat of the glomerulus with cells leaking into the stroma indicating substance administered is toxic to the kidney.

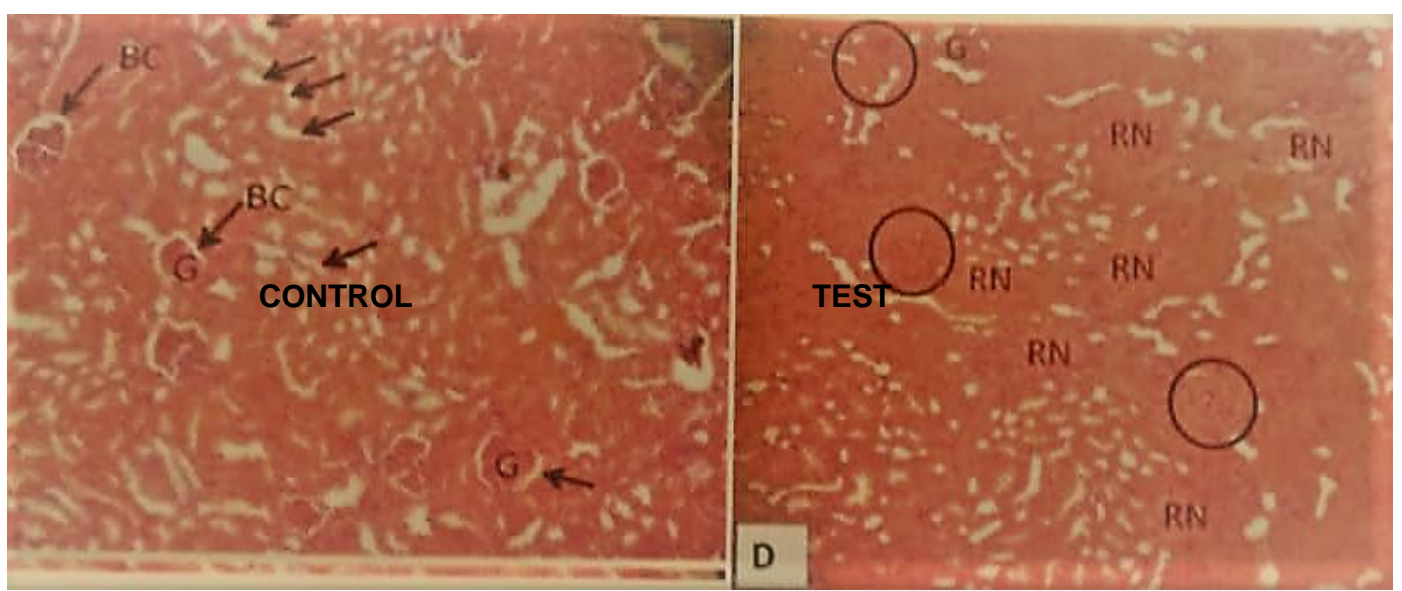

Figure 2: Haematoxylin and Eosin stain kidney Tissue, X 400 Magnification

Heart: Photomicrograph of the heart tissue showing normal histology. Both Test and control are consistent with normal histology of the heart. Substance administered is non- toxic to the tissue.

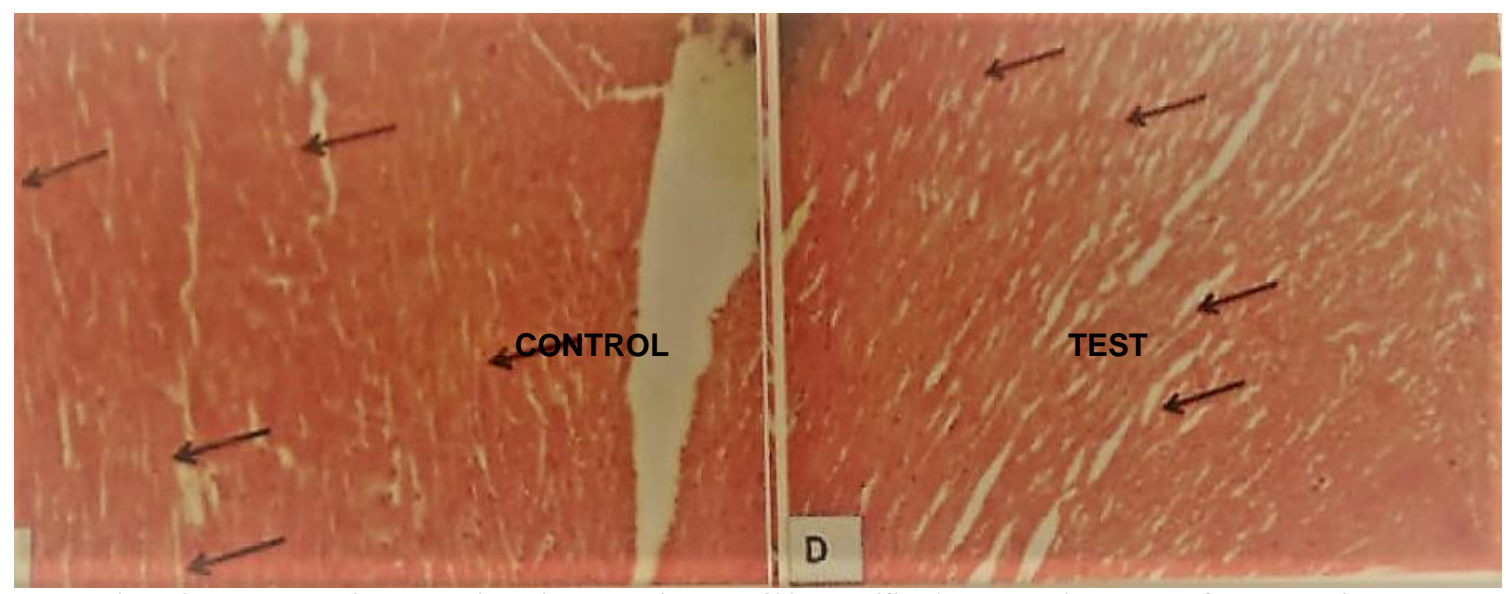

Figure3: Haematoxylin and Eosin stain heart Tissue, X 400 Magnificationphotomicrograph of the heart tissues.

Both the Control and Test groups had parallel pattern of myofibril with centrally located nuclei (arrows) along their branches. 


\section{DISCUSSION}

One quarter of all prescription drugs come directly from or are derivatives of plant ${ }^{[22]}$ also traditional medicine uses numerous plant. Tea beverage is an infusion of the dried leaves of camellia sinensis. Lime belongs to the group of citrus fruits. The effect of the decoction of lime citrus aurantifolia and Camellia sinensis (Lipton tea) on the plasma glucose, plasma total protein, albumin concentration and weight of the normal albino rats were examined.

Glucose levels in the blood of rats can be reduced by epigallocatechin gallate as shown in rodent which can be effective in preventing the development and treatments of type 2 diabetes [23]. Green tea polyphenols also increase insulin activity in diabetic rats. It is also documented that the water soluble polysaccharides fraction of green tea is responsible for its anti-diabetic effect ${ }^{[24]}$. Data from our study showed that there was decrease in glucose concentration and effect could be attributed to the presence of polyphenols in the decoction of lime and Lipton tea which agreed with previous reports ${ }^{[23,25]}$.

Data from our study revealed that total plasma proteins were also significantly decreased in the test group compared to the control group. This decrease in total protein concentration may be due to increased concentration of polyphenols (flavonoids) present in the decoction of lime and lipton tea.

Studies have shown that citrus aurantifolia and camellia sinensis are rich in phytochemicals such as citric acid, ascorbic acid, dietary fiber, flavonoids, saponin, terpenoids, steroids and alkaloids [6]. Sayama et al., ${ }^{[26]}$ reported that the addition of green tea powder to the diet suppressed fat accumulation and body weight increase without reduction of food intake in mice. Green tea has been reported to reduced body weight, body mass index and fat ${ }^{[27]}$. These findings are in agreement with our results which showed that the Test control reduced in weight compared to the Control group.
Data from our results revealed that there was no significant change in the plasma albumin concentration which is consistent with previous report which demonstrated that was no significant difference in the levels of serum protein, albumin and total and direct bilirubin of moderate drinkers ${ }^{[28]}$.

Histological studies showed that the decoction of lime and lipton tea had a toxic effect on the liver and kidneys but had no effect on the heart, this may be due to concentration and doses administered.

\section{CONCLUSION}

The results obtained suggests that the presence of polyphenols(flavonoids) in lime and lipton tea respectively may be responsible for the decrease in plasma glucose and total protein concentrations respectively which is clinically significant for diabetic patient and treatment of obesity. However, the concentration and doses administered could have adverse effect on the liver and kidneys.

\section{Acknowledgement: None}

\section{Conflict of Interest: None}

\section{Source of Funding: None}

\section{Ethical Approval: Approved}

\section{REFERENCES}

1. Aja, P. M., Alum, E. U., Ezeani, N. N., Ibiam, U. A., and Egwu, C. Comparative phytochemical evaluation of Dissotis rotundifolia root and leaf. Global Vet. 2015;14(3): 418-424

2. Sharangi, A. B. Medicinal and therapeutic potentialities of tea (Camellia sinensis), A review food Research International. 2009; 42:529-535.

3. Stangl, V, Dreger, $\mathrm{H}$, Stangl ,K and Lorenz, M. Molecular targets of tea polyphenols in the cardiovascular system. Cardiovascular Research, 2007;73,348358.

4. Maruyama K, Kihara-Negishi F,Ohkura N,Nakamura,Y,Nasui $M$ and Saito,M. 
Simultaneous determination of Catechins and Caffeine in Green Tea-based beverages and foods for specified health Uses, Food and Nutrition sciences 2017;8:316-325.

5. Cheyneir, V.(2005).Polyphenols in foods are more complex than often thought. Amer socclin Nutr, 2005;81,225-229.

6. Delcaro, A, Piga, A, Vacca, V and Agabbio, M. Changes of flavonoids, vitamin $\mathrm{C}$ and antioxidant capacity in minimally processed citrus segments and juices during storage food Chem..2004;84:99-105.

7. Sanaka S, Aizawa M, Kim $M$ and Yamamolol T. Inhibitory effect of green tea polyphenols on growth and adherence of an oral bacterium, Porphyromonas gingivalis. Bioscience Biotechnology Biochemistry, 1996;60,745-749.

8. Reygaert W.C (2014).The antimicrobial possibilities of green tea; frontiers in microbiology 2014;5:434(1-8).

9. Katiyar S.K,Ahmad N. and Mukhtar H. Green Tea and Skin; Arch Dermatol. 2000;136(8):989-9964.page 16.

10. Kao,Y.H,Chang H.H.,Lee,M.J. and CHENG,C.L. Tea, Obesity and Diabetes, Mol Nutr Food Res.2006;509(2):188-210.

11. Boschmann, M. and Thielecke, F. The effects of epigallocatechin-3-gallate on thermogenesis and fat oxidation in obese men:a pilot study.J.AM Coll Nutr. 2007;26(4):389s-395s page 14.

12. Chandra, A. M. and De, N.. Goitrogenic and antithyroid potential of Green Tea of Indian origin; Bangladesh soc physiol 2014; 9(2):105-116.page 16.

13. Kurowska, E.,Spence, J.D., Jordan,J., Wetimore,S., Freeman,D.J., Piche,L.A., Serratore,P. HDL Cholesterol-raising effect of dietary orange juice in subjects with hypercholesterolemia, AM J.Clin. Nutr.2000;72:1095-1100.

14. Kostyuk,V.A,

Potapovich,A.I, Vladykovskaya E.N, Hiramatsu,M. Protective effects of green tea catechins against Asbestos-induced cell injury. Planta Med 2000;66:762-764.

15. Guo.S, Yan ,J.,Yang, T.,Yang, X,Bezard, $\mathrm{E}$ and Zhao,B. Protective effects of green tea polyphenols in the 6-OHDA rat model of Parkinson's disease through inhibition of ROS-NO pathway; Biol psychiatry. 2007;62:1353-1362.

16. Sethpakdee R. Citrus aurantifolia (christen and panzer) Swingle.In:R.E.Coronel and E.W.Verheij.(Eds):Plant Resources of South-East Asia.Edible fruits and nuts. Prosea

foundat4.ion,Bogor,Indonestia.2:126128.1992

17. Okwu D.E (2008).Citrus fruits: a rich source of phytochemicals and their roles in human health;a review. International Journal of Chemical science.2008; 6(2):451-471.

18. Nwachukwu,E ,Onovo,O.M and Ezeama, C.F. Effect of Lime Juice on the Bacterial Quality of Zobo Drinks Locally Produced in Nigeria. Research Journal of Microbiology.2007;2:789-791.

19. Kunow M. A. Maya Medicine:Traditional Healing in Yucatan.UNM Press,New Mexico.117.2003

20. Khan, S. A., Priyamvada, S, Farooq, N., Khan, S., Khan M.W.,Yusufi, A.N.K: Protective effect of green tea extract on gentamicin- induced nephrotoxicity and oxidative damage in rat kidney. Pharmacological Research,2009;59:254262.

21. Aibinua, I., Adenipekun T., Adelowotan $\mathrm{T}$, Ogunsanya, T, Odugbemi,T .Evaluation of Citrus aurantifolia(lime fruits) as used locally.African Journal of Traditional complement and Alternative Medicine.2007;4(2):185-190.

22. Lin,J.K., Lin-Shiau,S.Y. Mechanism of hypolipidemic and anti-obesity effects of tea and tea polyphenols, Mol.Nutr.food Res.2006;50,211-217.

23. Anderson,N.L., and Anderson,N.G. The Human Plasma Proteome. Molecular and Cellular Proteomics 2002;1,845-867.

24. Isigaki, K., Takakuma, T., Takeo, T. Antidiabetes mellitus effect of water-soluble tea polysaccharide.The organizing committee of ISTS.1991;240-241.

25. Song, E.K., Hur, H. Han, M.K.,(2003), Epigallocatechum gallate prevents autoimmune diabetes induced by multiple low doses of streptozotocin in mice. Arch. pharm. Res 2003;26(7).559-63. 
Ojoye Preiye et.al. The effect of the decoction of citrus aurantifolia (Lime) and camellia sinensis (Lipton Tea) on the plasma glucose; plasma total protein, albumin concentrations and weight of normal albino rats.

26. Sayama K., Lin. S., Zheng, G., Oguni. I. Effects of green tea on growth, food utilization and lipid metabolism in mice. In vivo.2000;14,481-484.

27. Tsuchida T., Hakura, H.,Nakamura,H. Reduction of body fat in humans by longterm ingestion of catechins. Progress. Med.2002;22,2189-2203.

28. Yakubu. M.T. Bilbis,L.S., Lawal,M and Akanji, M.A. Evaluation of selected parameters of rat liver and kidney function following repeated administration of
Yohimbine. Nigerian Journal of Biochemistry and Molecular Biology. 2003; 15(2):50-56, page 25.

How to cite this article: Preiye O, Patricia TE, Eric BV et.al. The effect of the decoction of citrus aurantifolia (lime) and camellia sinensis (lipton tea) on the plasma glucose; plasma total protein, albumin concentrations and weight of normal albino rats. Int J Health Sci Res. 2021; 11(7): 81-88. DOI: https://doi.org/ 10.52403/ijhsr.20210712 